\title{
Charges e histórias em quadrinhos através da composição de imagens: estratégias de ensino na Educação Básica em Geografia
}

Fernando Frederico Bernardes*

Resumo: Este artigo relata uma prática de ensino desenvolvida na segunda etapa do primeiro ciclo do Ensino Médio da Escola de Educação Básica Feevale - Escola de Aplicação. A proposição examina as relações capitalistas do espaço geográfico, através da construção de charges ou histórias em quadrinhos, objetivando a percepção/visualização individual de cada aluno em relação à prática e à dinâmica capitalista pretérita e/ou contemporânea. Os resultados deste trabalho se expressam na construção de produtos de interpretação, demonstrando o posicionamento dos alunos em relação às ações capitalistas e as suas transformações dentre o espaço geográfico. A intenção é tornar útil esta sugestão/reflexão de prática de ensino, independente do nível de escolaridade, seja ela no ensino fundamental ou médio, no âmbito público ou privado, concretizando o sentido da intenção da proposta deste artigo.

Palavras-chave: Charge; Educação Básica; Geografia; Imagem; Prática de Ensino.

Abstract: This article reports on a teaching practice developed in the second stage of primary school, School of Basic Education Feevale - Application School. The proposition examines the capitalist relations of geographical space, through the construction of cartoons or comics, aiming at the perception / view of

Mestre em Geografia pela Universidade Federal do Rio Grande do Sul. Professor da Escola de Aplicação da Universidade Feevale. E-mail: ffbgeo@gmail.com 
each individual student in relation to the practice and dynamic capitalist past and / or contemporary. These results are expressed in product of interpretation, showing the placement of students in relation to actions capitalists and their transformations among the geographic space. The intention is to make this useful suggestion / reflection of teaching practice, regardless of educational level, whether in elementary or high school, in public or private, realizing the meaning of the intent of the proposal of this article.

Keywords: Charge; Basic Education; Geography; Image; Practice of Teaching.

As diferentes leituras, em Geografia, podem ser realizadas de várias maneiras: através da interpretação de mapas, análise de imagens, textos, observações de campo... Kaercher (1998, p. 14) aponta que se faz necessário alfabetizar o aluno em Geografia e que o capacite para a leitura-entendimento do espaço geográfico.

As metodologias para alcançar esses apontamentos/necessidades/capacidades são muitas, cabe aos profissionais da área orientar/direcionar a ação educativa numa perspectiva crítica da Geografia Escolar.

A(s) geografia(s) crítica(s) escolar(es), portanto, concebida(s) nestes termos, devem ser ao mesmo tempo uma forma concreta de prática educativa e um vir-a-ser, isto é, estará sempre "em construção" mesmo sendo implementada (VESENTINI, 1989, p. 75).

Não raro, os alunos da educação básica, de uma forma geral, manifestam o interesse em variar as dinâmicas das práticas de ensino. O quadro-verde (negro ou também branco) e o clássico e tradicional livro didático, ainda persistem, neste início de século, porém de uma forma coadjuvante, utilizando-os como apoio no desenvolvimento dos conteúdos geográficos.

Na concepção de Bernardes (2010, p. 109), o livro didático deve servir como apoio pedagógico, não pode ser excluído, principalmente por aquelas escolas que detêm estudantes mais carentes, onde muitas vezes é a única obra que o aluno possui 
em sua casa. Além disso, as ilustrações que os livros apresentam podem ser atrativas para os alunos enriquecerem o seu desejo em aprender e construir o conhecimento geográfico.

Logo, o presente artigo propõe-se a pensar sobre o espaço geográfico de uma maneira não tradicional, reproduzindo cenários a partir da criação de charges ou histórias em quadrinhos. Nessa criação/edição tem como objetivo desencadear a criatividade do aluno, promovendo a análise e a interpretação de um conjunto de informaçóes e objetos, que nos permitem ultrapassar a forma clássica/tradicional de compreensão e leitura do espaço geográfico.

As composições visuais construídas pelos alunos elegeram uma perspectiva mais crítica do que humorística, já que a palavra charge, segundo o dicionário Aurélio, 2004, diz que pode ser simplesmente uma representação pictórica, em que se satiriza um fato específico, em geral de caráter político e que é de conhecimento público. Portanto, a charge pode ser entendida como uma imagem, um desenho de natureza caricatural, ser satírica e/ ou com humor, representando pessoa, fato ou ideia. Conforme Gil (2009, p. 03), foi por volta do século XIX, que opositores aos governos expressavam a repressão que sofriam e estes foram ganhando popularidade, persistindo até os dias de hoje.

A temática abordada para a elaboração das composições visuais foi sobre as características gerais do sistema capitalista e a sua influência na construção do espaço geográfico. Nesse sentido, as charges e histórias em quadrinhos foram elaboradas numa perspectiva crítica, (re)presentando, (re)construindo e/ou (re)organizando as diferentes marcas que o capitalismo deixa na paisagem, cabendo à Geografia e às suas práticas pedagógicas explicar essas marcas e estabelecer inter-relações no tempo, no espaço e com o próprio sujeito.

Para Moraes, 1999, p. 126:

A unidade da geografia crítica manifesta-se na postura de oposição a uma realidade social e espacial contraditória e injusta fazendo-se do conhecimento geográfico [...] Portanto, o caminho da geografia crítica 
é a busca da superação das desigualdades, pois a história do capitalismo leva à seletividade, estabelece uma divisão territorial e social do trabalho, diferencia e privilegia lugares. Para os "geógrafos críticos" é tal processo que deve ser objeto de preocupação na leitura do mundo, feita pela geografia.

Esta produção de prática de ensino elegeu a temática em evidência, pois nesta etapa do ensino médio, contempla-se este conteúdo, em sua programação. Assim, é importante ter sempre a preocupação de se considerar o nível de conhecimento do aluno, suas habilidades para dominar e desenvolver determinado conteúdo. Ressalto a importância de respeitar o seu saber, enquanto ponto inicial, para a reflexão de suas próprias experiências e as de outras situações do mundo contemporâneo.

Considerando a perspectiva de abordagem e o modo de produção do espaço geográfico, a intenção é de levar o aluno à construção e à reflexão de que o mundo está em transformação, e que o modo de produção capitalista interfere na realidade própria de cada um, tornando possível o desdobramento de outras questões ou ferramentas, de acordo com o que consta em determinada realidade.

Nesse sentido, a proposta inicial do trabalho seria a construção de histórias em quadrinhos com o auxílio do software Hagaquể, produzido pela Unicamp. Esse programa pode ser baixado de forma gratuita e proporciona um novo meio de prática de ensino, aliado às novas tecnologias.

Essa é uma proposta de prática de ensino bastante viável para o Ensino Médio (independente da esfera pública ou privada), em virtude da obrigatoriedade da instalação de, no mínimo, um laboratório de informática, nas instituiçôes de ensino, para a regulamentação, oficialização e funcionamento desta etapa da Educação Básica. A LDB (1996) expressa que o currículo do ensino destacará a educação tecnológica básica, de forma que o aluno, ao final do Ensino Médio, demonstre domínio dos princípios científicos e tecnológicos que conduzem a produção moderna e o conhecimento das formas contemporâneas de linguagem. 
Entretanto, o software Hagaquể é incompatível com o Sistema Operacional Windows $®$ 7, instalado nos equipamentos da Universidade Feevale, onde foi desenvolvida a prática de ensino. Por questões de segurança do próprio sistema, o mesmo tende a criar e apagar arquivos destinados ao c: $\backslash$ da máquina, na qual o usuário não tem a permissão de modificar. $\mathrm{E}$, não tendo essa permissão, o software não funciona.

Em virtude das razões mencionadas, os alunos da segunda etapa do primeiro ciclo do Ensino Médio da Escola de Aplicação, construíram as charges e as histórias em quadrinhos somente utilizando as ferramentas do Microsoft Office ${ }^{\circledR}$ e imagens da Internet. Alguns optaram em utilizar o Microsoft Office Word $\AA$, outros pelo Microsoft Office PowerPoint ${ }^{\circledR}$, ou então o Microsoft Office Picture Manager ${ }^{\circledR}$, porém todos com a mesma finalidade. A opção por determinado software ou caminho percorrido foi de livre escolha do aluno (afinidade, frequência de uso...), tornando-se facilmente aplicável, na elaboração do trabalho em questão.

Estimulados, a partir de charges e histórias em quadrinhos já prontas, disponíveis na internet, utilizou-se o projetor multimídia, para expor algumas amostras, com o intuito de despertar a linguagem criativa dos alunos, levando-os a produzirem suas próprias impressões, utilizando as ferramentas do Microsoft Offi$c e ®$. De acordo com as suas habilidades instrumentais, os alunos utilizaram imagens disponíveis na rede, e criaram suas próprias composições, sejam elas em formato de charge ou de histórias em quadrinhos, fornecendo subsídios didático-pedagógicos, conteúdos e habilidades para a construção das mesmas.

Essas dicas são exemplos de que é possível, sem gastos extras ou recursos extraordinários, criar atividades que levem os alunos a perceber o espaço geográfico de forma mais plural e dinâmica. Podemos romper a indiferença dos alunos em relação à disciplina (KAERCHER, 2007, p. 32).

O conteúdo das composições das imagens remete, diretamente, à ideia dos PCNs (1998, p. 22), onde se admite que, na educação do Ensino Básico, é essencial abordar o olhar marxista 
em relação ao processo de produção do espaço geográfico e as suas desigualdades sociais.

É inegável a contribuição do marxismo para o aluno compreender e explicar o processo de produção do espaço. É por meio dele que se poderá chegar a compreender as desigualdades na distribuição da renda e da riqueza que se manifestam no espaço pelas contradições entre o espaço produzido pelo trabalhador e aquele de que ele se apropria, tanto no campo como na cidade. Nesse sentido, categorias do marxismo como relações sociais de produção, modos de produção, meios de produção, forças produtivas, formação social, são fundamentais para revelar ao aluno condições concretas do seu cotidiano na sociedade.

O PNLEM (2009, p. 34), acrescenta, também, que, algumas obras (livros didáticos), do Ensino Médio apresentam uma proposta construtivista, em termos metodológicos, e tem, como fundamentação teórica, o materialismo histórico, doutrina segundo a qual o conhecimento do espaço parte de sua compreensão como produto do trabalho e das desigualdades sociais.

Portanto, essa leitura que enfatiza as desigualdades sociais foi um dos principais objetivos para construir as composições de imagens (charges ou histórias em quadrinhos). Outros objetivos também foram contemplados, tais como: praticar a leitura visual (não-verbal), verificar que a charge possui um contexto, não deve ser vista de maneira isolada, pois informa e opina sobre uma determinada temática (representação de mundo). Além de todos esses objetivos mencionados, cabe citar, ainda, se não evidenciar como principal, o de atrair os alunos para uma leitura diversificada, preparando-os para outras interpretações de cunho social, promovendo-lhes uma visão crítica da realidade social, o que justifica, também, um uso criativo da linguagem. Segundo Castrogiovanni (2007, p. 44), o Ensino Básico, neste início de século, chamado pós-moderno, deve indicar, aos seus alunos, propostas desafiadoras, capazes de despertar o interesse dos sujeitos, aplicando-as no seu cotidiano e na sua própria vida. Concluída a proposta de ensino, foram selecionados três resultados: o primeiro (Figura 1) retrata as desigualdades sociais, evidenciando a acentuada discrepância econômica e social no 
mundo contemporâneo. O segundo resultado (Figura 2) representa a evolução do sistema capitalista e as diferentes relações, de acordo com o tempo e espaço. Na última impressão (Figura 3), a intenção do aluno foi de abordar a corrupção que, infelizmente, impera na atual democracia brasileira, que, também, podemos chamar de democracia neoliberal. Para tanto, os resultados priorizaram o diálogo e a atividade intelectual do aluno, estimulando-o a selecionar e a analisar informações, a estabelecer relações entre os fatos, a raciocinar e a expressar-se com criatividade e coerência.

Figura 1

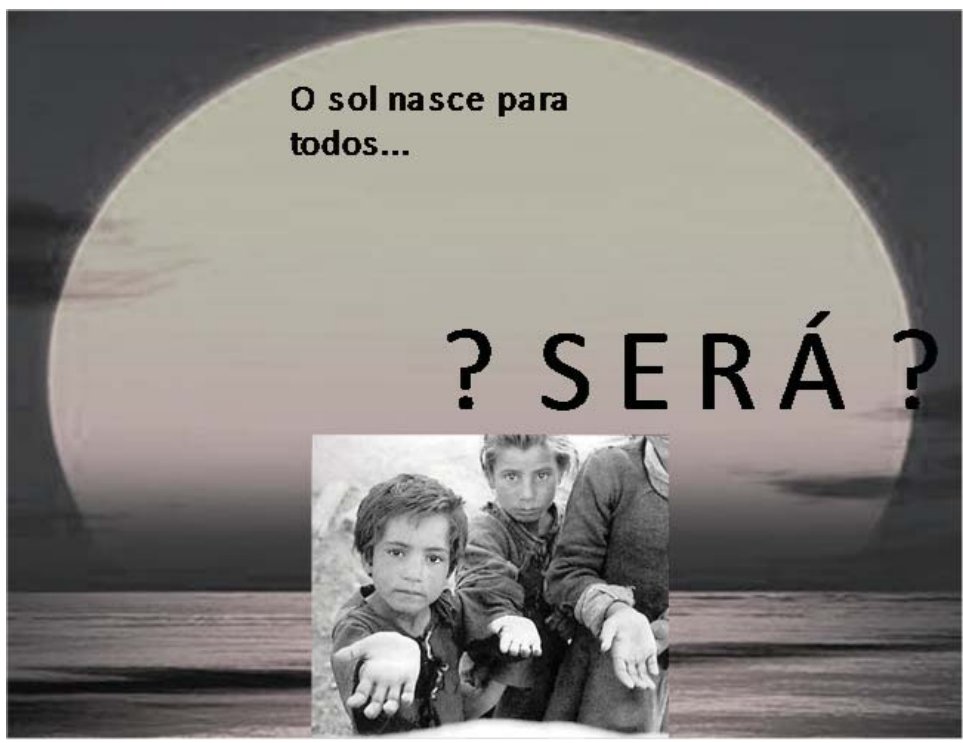


Figura 2
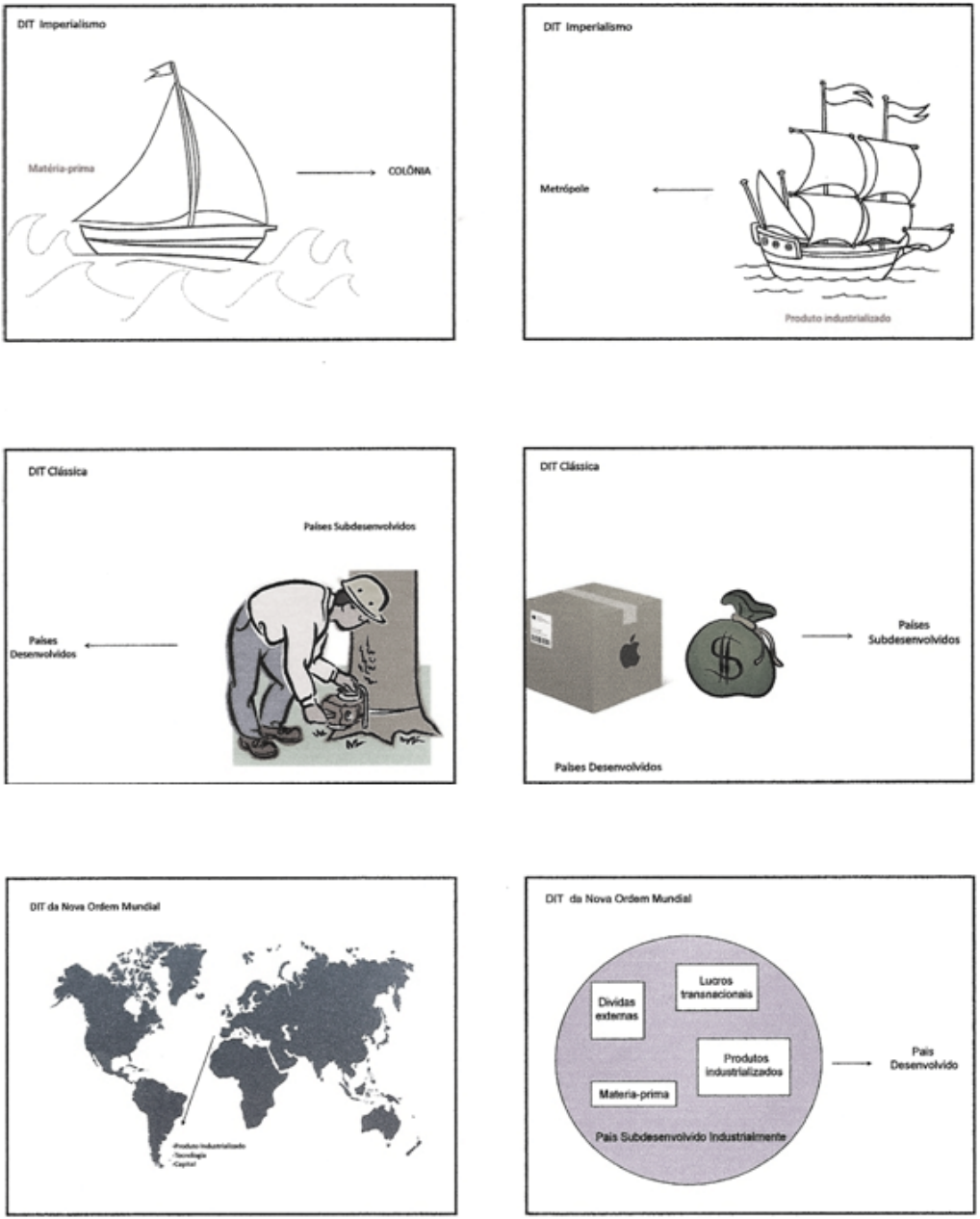


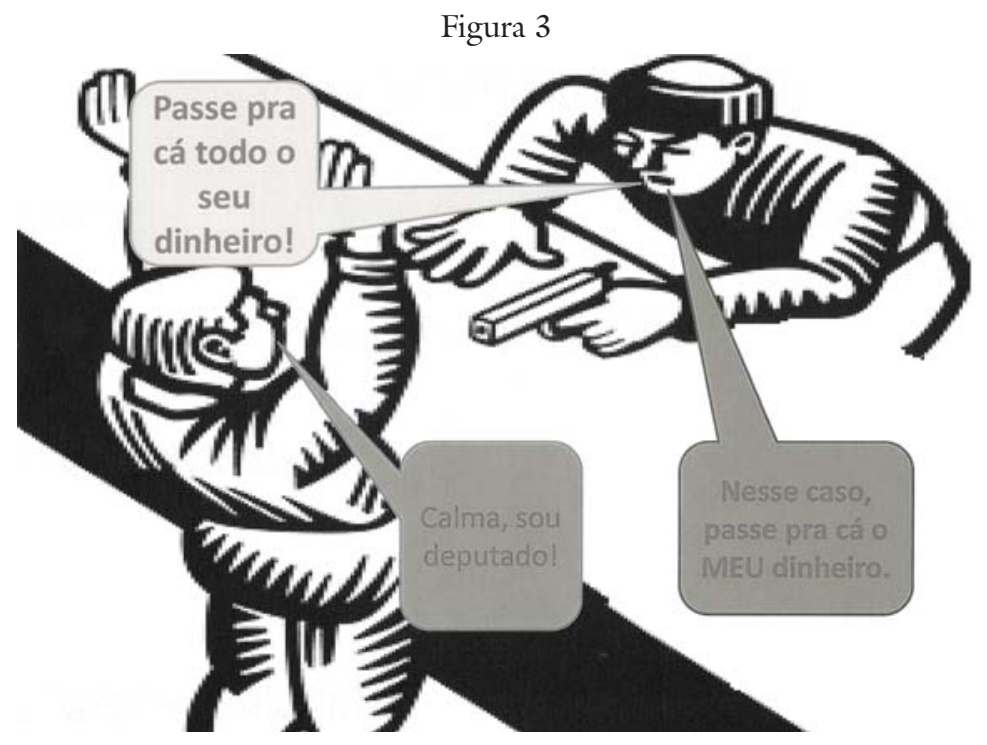

Nesse processo (de construção e reflexão das charges ou histórias em quadrinhos), é preciso considerar que a elaboração e a reflexão, sobre as mesmas, partiu desse conhecimento fundamental dos alunos (vivências, experiências de vida), do conteúdo formal (disciplina) e do próprio conhecimento docente (explanação dialógica). Ao mesmo tempo, possibilitou, não apenas uma oportunidade de aprendizagem, mas também a compreensão da realidade e da construção de um cidadão crítico que participe da construção dessa realidade.

Os resultados despertaram, nos alunos, os sentidos sociais e ideológicos, fazendo-lhes entender a charge como um discurso, mesmo que, às vezes, haja a ausência de frases ou palavras. Essa proposta também lhes prorcionou um estudo da Geografia, de forma qualitativa, permitindo-lhes conhecer outras formas de discursos, expressando suas opiniões e enriquecendo os debates sobre as diferentes realidades das diferentes paisagens do espaço geográfico. Contudo, as charges (composições visuais) foram 
variadas: algumas humorísticas, outras irreverentes ou apenas críticas, buscando conscientizá-los da importância do conhecimento da Geografia para ele, já que eles fazem parte da Geografia, de um determinado contexto e espaço geográfico. A execução desses trabalhos possibilitou uma forma de descontração, tornando as aulas de Geografia mais dinâmicas e enriquecedoras, despertando o interesse dos alunos sobre o conteúdo ou temática desenvolvida, diminuindo, ou até mesmo, extinguindo a aversão, de alguns, em relação à disciplina.

\section{Referências}

BERNARDES, Fernando Frederico. (Meio) ambiente: rompendo paradigmas na produção científica e no ensino da geografia e da biologia. 124fl. 2010. Dissertação (Mestrado). Universidade Federal do Rio Grande do Sul. Instituto de Geociências. Programa de Pós-Graduação em Geografia, Porto Alegre, 2010

BRASIL. Ministério da Educação (MEC), Secretaria de Educação Fundamental. Parâmetros Curriculares Nacionais: terceiro e quarto ciclos: apresentação dos temas transversais. Brasília: 1998.

BRASIL. Ministério da Educação (MEC), Secretaria de Educação Básica, Fundo Nacional de Desenvolvimento da Educação. Geografia: catálogo do Programa Nacional do Livro para o Ensino Médio: PNLEM/2009. Brasília: 2008.

CASTROGIOVANNI, Antônio Carlos. Para entender a necessidade de práticas prazerosas no ensino de geografia na pós-modernidade. In: REGO, Nelson; CASTROGIOVANNI, Antônio Carlos; KAERCHER, Nestor André (Orgs.). Geografia: práticas pedagógicas para o ensino médio. Porto Alegre: Artmed, 2007.

FERREIRA, Aurélio Buarque de Holanda. Dicionário Aurélio Básico da Língua Portuguesa. Rio de Janeiro: Nova Fronteira, 2004.

GIL, Edilene Alessandra. Gêneros textuais: propaganda e charge. Disponível em: <http://pt.scribd.com/doc/34048391/PLANO-DE-AULA- 
SOBRE-OS-GENEROS-TEXTUAIS-CHARGE-E-PROPAGANDA>. Acesso em: 18 de maio 2011.

KAERCHER, Nestor André. A Geografia é o nosso dia-a-dia. In: CASTROGIOVANNI, Antônio Carlos; CALLAI, Helena Callai; SCHÄFFER, Neiva Otero; KAERCHER, Nestor André. (Orgs.). Geografia em sala de aula: práticas e reflexões. Porto Alegre: AGB, 1998.

KAERCHER, Nestor André. Práticas geográficas para lerpensar o mundo, converentendersar com o outro e entenderscobrir a sim mesmo. REGO, Nelson; CASTROGIOVANNI, Antônio Carlos; KAERCHER, Nestor André (Orgs.). Geografia: práticas pedagógicas para o ensino médio. Porto Alegre: Artmed, 2007.

MORAES, Antonio Carlos Robert. Geografia: pequena história crítica. 17. ed. São Paulo: Hucitec, 1999.

SILVEIRA, Célia; PETER, Diva. (Orgs.). Cadernos universitários 006: Legislação Básica da Educação Brasileira. Canoas: ULBRA, 2003.

VESENTINI, José William. Geografia e ensino - textos críticos. São Paulo: Papirus, 1989. 